\title{
Pathogenesis of chondrocalcinosis and pseudogout. Metabolism of inorganic pyrophosphate and production of calcium pyrophosphate dihydrate crystals
}

\author{
A. CASWELL, D. F. GUILLAND-C UMMING, P.R. HEARN, M.K. B. MCGUIRE, \\ R. G. G. R USSE L L \\ From Department of Human Metabolism and Clinical Biochemistry, University of Sheffield Medical School, Beech Hill \\ Road, Sheffield S10 2RX.
}

\section{Introduction}

Calcium pyrophosphate dihydrate (CPPD) is one of several types of crystal that may be deposited in the body. The term chondrocalcinosis is used to describe the radiographic appearance of calcified deposits, notably in the articular cartilage and menisci of the knees but also in other joints. ${ }^{1}$ Not all calcified deposits within joints are due to .calcium pyrophosphate; however, occasional deposition of apatite, ${ }^{2}$ calcium dihydrogen phosphate, ${ }^{3}$ and oxalate also occurs.

McCarty was the first to identify CPPD crystals in synovial fluids taken from patients thought to have gouty arthritis, ${ }^{1.5} \mathrm{He}$ found the crystals to be the calcium pyrophosphate dihydrate salt in its triclinic form. Shedding crystals into the synovial space produces acute or chronic attacks of pseudogout. $^{6}$

Certain considerations apply to all forms of crystal deposition, in particular the factors determining whether or not crystallisation occurs. This largely concerns the activity products of the ions involved, although the presence of nucleating agents or inhibitory agents, or both, must be considered. Solubilisation processes may also be important.

The purpose of this presentation is twofold: (a) to review current knowledge of the metabolism of inorganic pyrophrosphate and $(b)$ to describe some of the mechanisms that may be involved in the production of CPDD crystals, both in vitro and in vivo.

\section{General considerations}

Table 1 summarises the factors to be considered in relation to the deposition of CPPD crystals and the association of chondrocalcinosis with endocrine and metabolic diseases. The reasons for these clinical associations are not always clear but they indicate that a variety of metabolic disturbances may lead to deposition of pyrophosphate crystals.

CPPD deposition is also more common in the presence of other joint disease, including osteoarthropathy, ${ }^{5}$ neuropathic (Charcot) joint disease, ${ }^{7}$ and gout. ${ }^{5}$ In such cases the destructive changes that occur may induce alterations of pyrophosphate metabolism within the joint leading to increased crystal formation.

The increased incidence of CPPD deposition with aging may also be related to the changes that occur in cartilage with age.

A familial form of chondrocalcinosis was described by Zitnan and Sit'aj in $1958,{ }^{8}$ although at that time it was not known that CPPD was the calcium salt responsible. Subsequently other familial forms have been described. ${ }^{10-12}$ The existence of these inherited forms allow a comparison with classic gout where specific enzyme defects have occasionally been identified-for example, in the Lesch-Nyhan syndrome. ${ }^{13}$ The underlying metabolic defect in the familial forms of chondrocalcinosis is still not determined but may entail enzyme abnormalities.

Hypophosphatasia is an inherited disorder associated with pseudogout. ${ }^{1415}$ Here there is an enzyme defect, a deficiency of alkaline phosphatase with resultant rise of inorganic pyrophosphate $\left(\mathrm{PP}_{\mathrm{i}}\right)$ in body fluids. Hypophosphatasia is the best example of how an abnormality in pyrophosphate metabolism may contribute to the production of chondrocalcinosis, but raises the intriguing question of why CPPD crystals appear in the typical sites in cartilage, even though $\mathbf{P P}_{\mathrm{i}}$ concentrations are raised systemically.

It is apparent that chondrocalcinosis must be considered a multifactoral problem in which several metabolic and physiochemical factors probably interact to produce CPPD crystals. Before considering the mechanisms of crystallisation involved in production of CPPD crystals, we will first review current knowledge of pyrophosphate metabolism.

\section{Intracellular metabolism of inorganic} pyrophosphate

\section{GENERAL CONDITIONS}

Inorganic pyrophosphate $\left(\mathrm{PP}_{\mathrm{i}}\right)$ is produced at one or more steps in a wide variety of biochemical pathways that lead to the synthesis of most of the major cell constituents. Hence generation of $\mathrm{PP}_{\mathrm{i}}$ occurs during the biosynthesis of proteins, lipids, phospholipids, nucleotides, and nucleic acids, urea, steroids, structural polysaccharides, and glycogen. Breakdown of pyrophosphate is brought about by a hydrolysis reaction catalysed by inorganic 
Table 1 Conditions associated with deposition of crystals of calcium pyrophosphate dihydrate (CPPD) in joints (chondrocalcinosis). Note the large number of possible underlying mechanisms.

Possible mechanisms involved

Inherited forms:

Described from

Czechoslovakia, Chile, Netherlands, Sweden, France, USA

General associations: Aging

Other joint disease:

Osteoarthritis

Neuropathic joint disease (Charcot joints)

Destructive arthropathy

Ochronosis

Rheumatoid arthritis

Urate gout

Metabolic disorders:

Hyperparathyroidism

Hypothyroidism

Hypophosphatasia

Haemochromatosis

Long-term steroid therapy

Possible associations:

Hypertension

Renal insufficiency

Acromegaly

Paget's disease

Diabetes mellitus

Wilson's disease
Possible abnormality in inorganic pyrophosphate

$\left(\mathbf{P P}_{\mathrm{i}}\right)$ metabolism-for example, overproduction of $\mathrm{PP}_{\mathrm{i}}$ or decreased degradation of $\mathrm{PP}_{\mathrm{i}}$ (possible changes in pyrophosphatases)

Reduced inhibitors of crystallisation.

Disturbed $\mathrm{PP}_{\mathrm{i}}$ metabolism.

Physical damage to chondrocytes.

Release of nucleating agents or decreased inhibitory activity (perhaps via action of released proteases to destroy inhibitors). Increased cartilage permeation by $\mathrm{Ca}^{++}$and $\mathrm{PP}_{\mathrm{i}}$.

Epitaxy on apatite crystals. $\mathrm{pH}$ may be lowered during inflammation which promotes crystal transformations to more

Epitaxy on urate crystals

Raised extracellular $\mathrm{Ca}$, and/or raised $\mathrm{PP}_{\mathrm{i}}$ due to increased adenylate cyclase activity.

Metabolic changes in cartilage

Raised $\mathrm{PP}_{\mathrm{i}}$ due to alkaline phosphatase deficiency

$\mathrm{Fe}$ as nucleating agent or

pyrophosphatase inhibitor

Secondary hyperparathyroidism

High $\mathrm{PP}_{\mathrm{i}}$ in chronic renal failure; acidosis promotes crystal transformation to insoluble forms

Metabolic alterations in cartilage

Age related

Copper as crystal nucleating agent or pyrophosphatase inhibitor insoluble forms. pyrophosphatases, in which $2 \mathrm{~mol}$ of orthophosphate $\left(\mathrm{P}_{\mathrm{i}}\right)$ are produced per mol of $P_{i}$ cleaved. Such enzymes include glucose-6-phosphatase and alkaline phosphatase, as well as more specific inorganic pyrophosphatases.

The metabolic importance of $\mathbf{P P}_{i}$ has yet to be defined. The assumption that intracellular concentrations of $P_{i}$ are very low led Kornberg and others ${ }^{16}$ ${ }^{17}$ to point out that the removal of $\mathrm{PP}_{\mathrm{i}}$ provides a means of driving pyrophosphorylase reactions in the direction of synthesis, essentially rendering them irreversible. However, observations of detectable amounts of $\mathrm{PP}_{\mathrm{i}}$ in rat liver, for example, ${ }^{18}{ }^{19}$ question this assumption, and, moreover, question whether the concentration of intracellular $P_{P}$ would be under metabolic control and could respond to changes in the rates of either its synthesis or degradation. Furthermore, if the intracellular concentration of $\mathrm{PP}_{\mathrm{i}}$ does change in response to different metabolic conditions, it becomes possible for this ion itself to be involved in the regulation of metabolism.

IS THE PP $P_{i}$ HYDROLYSIS

REACTION IN EQUILIBRIUM?

Attempts to determine the equilibrium constant and free energy change for hydrolysis of $\mathrm{PP}_{\mathrm{i}}$ under stimulated physiological conditions have produced variable results. ${ }^{20-22}$ However, the reported tissue concentrations of $\mathrm{PP}_{\mathrm{i}}$ appear to exceed those calculated from values found for the equilibrium constant, ${ }^{18}{ }_{19}{ }^{23}$ supporting the view that the hydrolysis reaction is not in equilibrium. Using freeze-clamped rat tissues we have recently demonstrated that the total $\mathrm{PP}_{\mathrm{i}}$ content of skeletal muscle (50 $\mathrm{nmol} / \mathrm{g}$ ) is substantially higher than that found in liver, kidney, heart, and lung tissues $(20 \mathrm{nmol} / \mathrm{g}$ ) (unpublished observations). Similarly, with isolated human cells, it has been observed that fibroblasts and synovial cells contain less $\mathrm{PP}_{\mathrm{i}}$ than chondrocytes and bone cells. Furthermore, the higher $P P_{i}$ content of chondrocytes relative to fibroblasts appears to be correlated with differences in the rate of proteoglycan synthesis in these two cell types. ${ }^{24-26}$

Several studies have shown that both the total $\mathrm{PP}_{\mathrm{i}}$ content and the calculated cytoplasmic free $P_{i}$ content of freeze-clamped rat liver may change quite considerably after various short term or long term metabolic manipulations-for example, after administration of acetate or butyrate or after 48 hours' starvation..$^{18192123}$ Such studies have led to the suggestion that hepatic glucose uptake and phosphorylation are regulated predominantly by changes in the concentration of free $\mathrm{PP}_{\mathrm{i}}$ in cytoplasm, ${ }^{21}$ thereby indicating a role for $\mathbf{P P}_{\mathbf{i}}$ in metabolic regulation. An increase in the intracellular concentration of $\mathrm{PP}_{\mathrm{i}}$ in response to the stimulation of a biosynthetic pathway producing $\mathrm{PP}_{\mathrm{i}}$ has also been observed in isolated human articular chondrocytes after enhancement of 
glycosaminoglycan synthesis by treatment with xylosides. ${ }^{26}$

Raised intracellular concentrations of $\mathrm{PP}_{\mathrm{i}}$ have also been reported in isolated fibroblasts and lymphoblasts derived from patients of a French family with an hereditary form of chondrocalcinosis. ${ }^{12}{ }^{27}$ This observation raises the question of whether some of the hereditary forms of chondrocalcinosis are associated with overproduction of $\mathrm{PP}_{\mathrm{i}}$ in cells, due to an abnormality in one of the biosynthetic pathways generating $P_{i}$. Reports of abnormal cartilage matrix production in patients from two Swedish families with a hereditary form of this disease might support this view. ${ }^{12}{ }^{28}$

Hence evidence appears to indicate that the intracellular concentration of $\mathrm{PP}_{\mathrm{i}}$ does vary with such factors as cell type, metabolic conditions, and the presence of disease states, supporting the hypothesis that the hydrolysis reaction is not in equilibrium and that the concentration of this ion is under metabolic control.

CONTROL OF THE

IN TR ACELL U L AR

CONCENTRATION OF PP

Factors involved in the control of the intracellular $P P_{i}$ concentration have yet to be defined. As discussed above, $\mathrm{PP}_{\mathrm{i}}$ production will be controlled by those factors which regulate biosynthetic pathways containing $\mathrm{PP}_{\mathrm{i}}$ generating steps and it will be necessary to delineate the relative contribution of the different pathways to the overall rate of $\mathrm{PP}_{\mathrm{i}}$ production in the cell. $\mathrm{PP}_{\mathrm{i}}$ breakdown will be controlled by those factors which regulate inorganic pyrophosphate activity.

TISSUE DISTRIBUTION AND PROPERTIES OF INORGANIC PYROPHOSPHATASE

$A$ recent study of inorganic pyrophosphatase activity in the rat showed that the total activity varies quite considerably between tissues and that the total hepatic activity changes during development. ${ }^{29}$ These results imply that the total tissue activity of this enzyme is regulated, but it should be noted that the activities measured in this study under optimal conditions in vitro do not necessarily reflect the real activities in vivo.
Inorganic pyrophosphatase appears to be principally located in the cytosol. $^{30}{ }^{32}$ Smaller amounts of the activity occur in mitochondria. ${ }^{33}$ Inorganic pyrophosphatase activity has also been demonstrated in endoplasmic reticulum in some tissues, but this may be due to the presence of a glucose-6-phosphatase,,$^{34}$ which also possesses pyrophosphatase activity.

Studies of pyrophosphatase in the cytosol from various tissues (red blood cells, polymorphonuclear leukocytes, cartilage, dental pulp, etc.) have suggested that this enzyme is specific for $\mathrm{PP}_{\mathrm{i}}{ }^{31}{ }^{32}{ }^{36-39}$ has a $\mathrm{pH}$ optimum of $7-8$, requires $\mathrm{Mg}^{++}$for activity, is strongly inhibited by other divalent metal cations even in the presence of $\mathrm{Mg}^{++}$-for example, $\mathrm{Ca}^{++}, \mathrm{Fe}^{++}$, and $\mathrm{Cu}^{++}$and is also inhibited by fluoride ions. Several known inhibitors of alkaline phosphatase-for example, $P_{i}$, imidazole, and $\mathrm{CN}^{-}$have little inhibitory effect on this enzyme and this, together with its specificity, suggest that this inorganic pyrophosphatase activity is a function of a discrete enzyme and is not simply a function of alkaline phosphatase. Reports of the $\mathrm{Km}$ for $\mathrm{PP}_{\mathrm{i}}$ of a cytosolic inorganic pyrophosphatase are in the range $11-40 \mathrm{mmol}$, which may imply that the enzyme is not saturated with substrate under physiological conditions.

Mitochondrial inorganic pyrophosphatase activity occurs in two forms, one of which is membrane bound. Both forms resemble the cytosolic activity in that they are specific for $\mathrm{PP}_{\mathrm{i}}$, require $\mathrm{Mg}^{++}$for activity, have $\mathrm{pH}$ optimum of $7-8$ and are inhibited by divalent cations-for example, $\mathrm{Ca}^{++}-$and by fluoride. ${ }^{334041}$ The effects of $\mathrm{Mg}^{++}$and $\mathrm{Ca}^{++}$may be of particular relevance and we are at present examining the influence of the availability of these cations on the intracellular concentration of $\mathbf{P P}_{\mathbf{i}}$ in human articular chondrocytes and bone cells.

\section{Extracellular metabolism of inorganic pyrophosphate}

GENERAL CONSIDERATIONS

Although $\mathrm{PP}_{\mathrm{i}}$ occurs extracellularly in body fluids-for example, serum, plasma, urine, saliva, and synovial fluid, and large quantities also occur adsorbed to bone mineral, there is little information about the movement of $\mathrm{PP}_{\mathrm{i}}$ across cell membranes or about which organs make appreciable contributions to the $\mathbf{P P}_{\mathrm{i}}$ content of extracellular fluid. There is evidence that this $\mathrm{PP}_{\mathrm{i}}$ is of endogenous origin; thus it is not derived direct from the diet, as dietary $P_{i}$ and polyphosphates appear to be completely hydrolysed to $P_{i}$ within the intestinal lumen, probably by the action of alkaline phosphatase, which is present in the brush border membranes of enterocytes. ${ }^{42}$

Studies of $\mathrm{PP}_{\mathrm{i}}$ turnover have been restricted to the examination of extracellular $P P_{i}$. Studies using ${ }^{32} \mathrm{P}$-labelled $\mathrm{PP}_{\mathrm{i}}$ indicate that plasma $\mathrm{PP}_{\mathrm{i}}$ turns over extremely rapidly in dogs and in man. ${ }^{43}$ In dogs the hydrolysis to $P_{i}$ accounts for at least $25 \%$ of the loss of $\mathrm{PP}_{\mathrm{i}}$ from the plasma compartment whereas urinary excretion accounts for only $10 \% .^{43}$ Hence hydrolysis to $P_{i}$ would appear to be a major mechanism for the removal of $\mathrm{PP}_{\mathrm{i}}$ from the plasma compartment. ${ }^{32}$ P-labelled $\mathrm{PP}_{\mathrm{i}}$ added to whole blood in vitro, however, is only relatively slowly hydrolysed, implying that the major hydrolytic enzymes are not circulating but are located on or within cells. $^{43}$

ORIGIN OF EXTRACELLULAR PP IN ARTICULAR CARTILAGE

If CPPD crystals are first formed outside cells rather than inside, then the origin of extracellular $\mathrm{PP}_{\mathrm{i}}$ and mechanisms controlling the local concentrations of this ion become important. (Fig. 1)

The $P_{\mathbf{i}}$ present in the extracellular space of articular cartilage could either arise from the intracellular compartment or it could be synthesised extracellularly or released from subchondral bone. Release of $\mathrm{PP}_{\mathrm{i}}$ from the intracellular compartment could occur by a variety of mechanisms-for example, by a specific membrane carrier for $\mathrm{PP}_{1}$, in conjunction with the secretion of matrix components or following cell damage or death.

THE RELEASE OF PPi FROM

ARTICULAR CARTILAGE

Generation of $P P_{i}$ in vitro by cartilage fragments was first reported by Howell's group, ${ }^{45}$ who stated that $\mathrm{PP}_{\mathrm{i}}$ was released from growth plate cartilage and from articular cartilage 


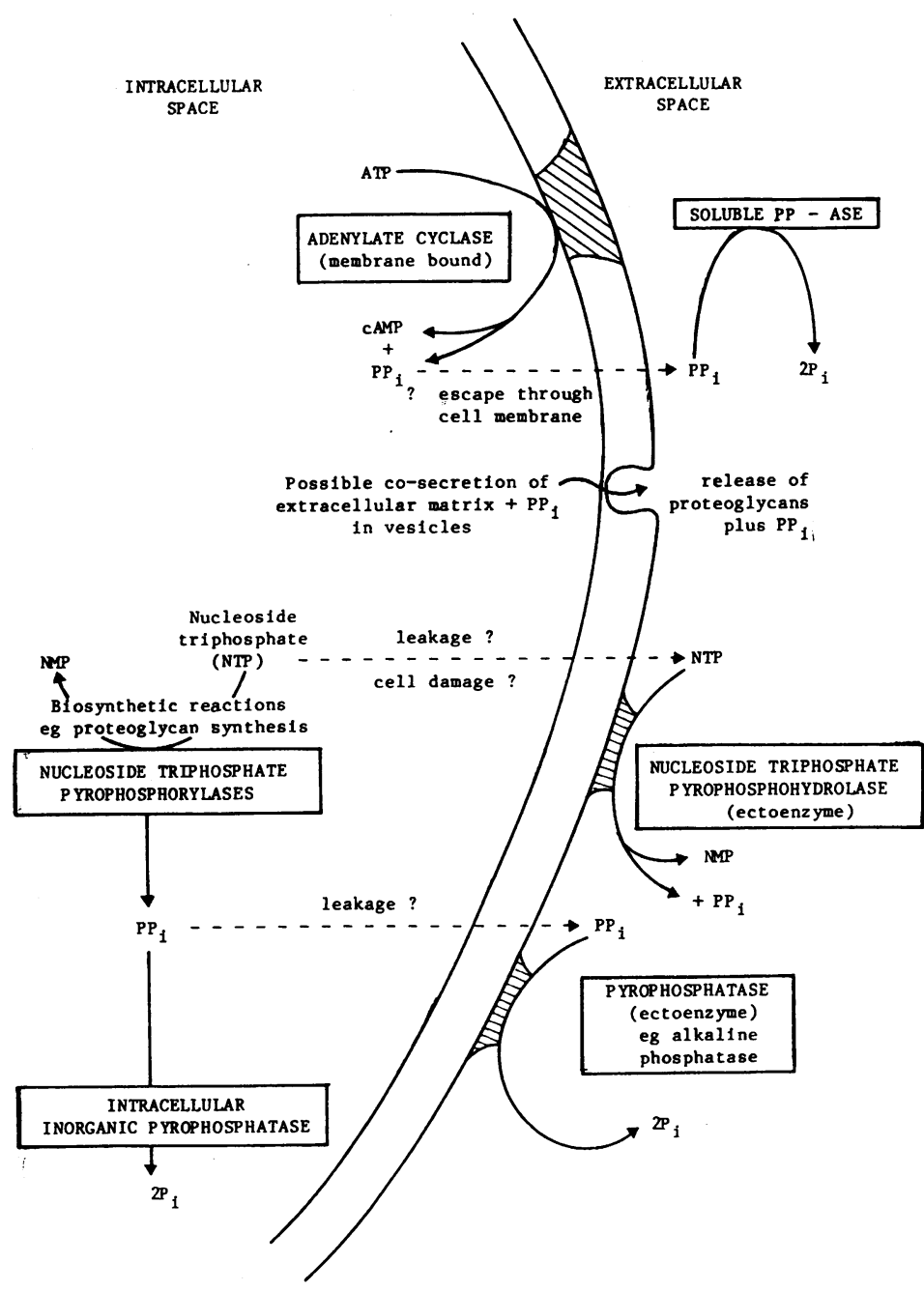

Fig. 1 Pyrophosphate metabolism: a schematic representation of possible sources of both intracellular and extracellular $P P_{i} . P P_{i}$ introduced in the intracellular compartment may be either co-secreted with products of intracellular biosynthetic reactions-for example, proteoglycans-or may leak to the extracellular compartment when cells are damaged, as happens in degenerative joint disease. Extracellular $P P_{i}$ may arise from the activity of the ectoenzyme, nucleoside triphosphate pyrophosphohydrolase, acting presumably on nucleoside triphosphates 'leaked' to the extracellular compartment.

derived from young rabbits and from patients with osteoarthritis but not from rabbit ear cartilage or from articular cartilage derived from mature rabbits or 'normal' humans. However, in a recent study, McCarty's group,,$^{46}$ using a highly sensitive assay and correcting for $\mathbf{P P}_{\mathrm{i}}$ hydrolysis during the incubation by the use of ${ }^{32} \mathrm{P}$-labelled $\mathrm{PP}_{\mathrm{i}}$, have observed release phosphate-buffered saline or medium without serum, no detectable release of $\mathrm{PP}_{\mathrm{i}}$ from these cells occurs. Furthermore, when the concentration of $\mathrm{PP}_{\mathrm{i}}$ in the medium is raised to around $100 \mu \mathrm{mol} / \mathrm{l}$ rapid hydrolysis of PP occurs. $^{24}{ }^{47}$ However, using a more sensitive assay, we have recently been able to demonstrate the release of small amounts of $\mathrm{PP}_{\mathrm{i}}$ from washed monolayers of human articular chondrocytes incubated in medium without serum. Additionally, we have observed that under our conditions, in which the extracellular PP $_{i}$ concentration is generally less than 1 $\mu \mathrm{mol} / \mathrm{l} \mathrm{PP}_{\mathrm{i}}$ hydrolysis determined with ${ }^{32} \mathrm{P}$-labelled $\mathrm{PP}_{\mathrm{i}}$ in the medium is very slow (A. M. Caswell and others, p. 99). This difference between our results and those of others ${ }^{47}$ may imply the presence of an extracellular inorganic pyrophosphatase activity with a relatively high $\mathrm{Km}$ for $\mathrm{PP}_{\mathrm{i}}$.

These various results suggest that chondrocytes possess the ability to release limited amounts of $\mathrm{PP}_{\mathrm{i}}$. In this context, it may be relevant that it has not been possible to show the passage of $\mathrm{PP}_{\mathrm{i}}$ across the membrane of the red cell. ${ }^{48}$ It is also of interest that, in the study of McCarty's group described above, release of $\mathrm{PP}_{\mathrm{i}}$ from rabbit cartilage fragments, but not from human cartilage fragments, was positively correlated with release of uronic acid. ${ }^{46}$ However, this does not necessarily establish that $P_{i}$ and uronic acid are released from the cell together since, as suggested earlier, changes in the rates of synthesis of matrix components could result in parallel changes in intracellular $P P_{i}$. Such changes could in turn influence the rate of release of $\mathbf{P P}_{\mathbf{i}}$ from the cell by any putative carrier mechanisms specific for $\mathrm{PP}_{\mathrm{i}}$. Release of $\mathrm{PP}_{\mathrm{i}}$ into the extracellular space of cartilage after damage or death of chondrocytes may. occur and could explain why patients who have had meniscectomies have a higher incidence of chondrocalcinosis in the operated knee than in the unoperated knee. ${ }^{49}$ The extent to which this release mechanism occurs in undamaged cartilage or in other 'normal' tissues is not known.

PRODUCTION OF PP

EXTRACELLULARLY

Another possible origin of extracellular $P P_{i}$ is that it is generated 
outside the cell by membrane bound enzymes. One such enzyme is adenylate cyclase which catalyses the reaction:

$$
\mathrm{ATP} \rightarrow 3^{\prime}, 5^{\prime} \text {-cyclic AMP + } \mathrm{PP}_{\mathrm{i}} \text {. }
$$

This enzyme is located in cell membranes and is activated in response to hormone and other agents-for example, certain drugs. ${ }^{\text {so }}$ The cyclic AMP formed is released into the intracellular compartment but the fate of $\mathrm{PP}_{\mathrm{i}}$ formed is unknown and it is not known whether any is released into the extracellular fluid.

Another enzyme of considerable interest is nucleoside triphosphate pyrophosphohydrolase, which catalyses the reaction:

NTP $\rightarrow$ NMP + PP $_{i}$, where NTP denotes nucleoside triphosphate and NMP nucleoside monophosphate.

In rat liver the enzyme is located in the plasma membrane, is calcium dependent and hydrolyses both pyrimidine and purine nucleoside triphosphates with $\mathrm{Kms}$ in the Molar range. ${ }^{51-53}$ The enzyme has been proposed to function either in calcium transport ${ }^{52}$ or together with 5 '-nucleotidase in the salvage of nucleoside triphosphates that leak from the cell. ${ }^{53}$ In rats this enzyme has been shown to exhibit a wide tissue distribution and the activity appears to vary quite considerably with tissue type, the highest activities being observed in liver, small intestine, and kidney and much lower activities being observed in brain, thymus, and blood. ${ }^{52}$

The presence of a nucleoside triphosphate pyrophosphohydrolase activity in human articular cartilage has been inferred from a recent study of Howell's group, who demonstrated the generation of $\mathrm{PP}_{\mathrm{i}}$ after adding 1 $\mathrm{mmol} / \mathrm{l}$ ATP to cartilage homogenates. ${ }^{54}$ However, the use of homogenates precludes any statement about the location of this enzyme activity or the number of possible activities involved.

We have been able to demonstrate the generation of substantial amounts of $\mathrm{PP}_{\mathrm{i}}$ extracellularly after adding ATP (concentration range $6 \cdot 25-400 \mu \mathrm{mol} / \mathrm{l}$ ) to washed human articular chondrocyte monolayers incubated in medium without serum (A. M. Caswell and others, p. 00). The effect can also be observed with other nucleoside triphosphates-for example, guanosine triphosphate, cytidine triphosphate, and uridine triphosphate. These preliminary observations suggest that presence of a highly active nucleoside triphosphate pyrophosphohydrolase on the outside of the plasma membrane of human articular chondrocytes with an apparently low $\mathrm{Km}$ for nucleoside triphosphates. The function of this activity in chondrocytes is unclear but could be similar to that suggested earlier for nucleoside triphosphate pyrophosphohydrolase activities in other tissues-for example, a role in calcium transport.

It is therefore interesting that the total concentration of nucleotides in the extracellular fluid of chicken epiphyseal cartilage has been reported to range from $200 \mu \mathrm{mol} / 1$ in the proliferating zone to $740 \mathrm{~mol} / \mathrm{l}$ in the hypertrophic zone. ${ }^{55}$ Thus there is a potential mechanism for the extracellular generation of $\mathrm{PP}_{\mathrm{i}}$, at least in growth cartilage, since appreciable amounts of $P P_{i}$ could be generated if nucleoside triphosphates comprised even a small fraction of the observed total nucleotide concentration.

It is also interesting to note that in the recent study by Howell's group described above, ${ }^{54}$ nucleoside triphosphate pyrophosphohydrolase activity was greater in articular cartilage homogenates derived from patients with chond rocalcinosis than in those derived from patients with osteoarthritis. One sample derived from a 'normal' patient contained virtually no activity. This apparent increase in the activity in a situation in which increased amounts of $\mathrm{PP}_{\mathrm{i}}$ occur extracellularly supports the view that this enzyme is important in the generation of $\mathrm{PP}_{\mathrm{i}}$ extracellularly in articular cartilage. Furthermore, there may be a role for this activity in the pathogenesis of chondrocalcinosis after cartilage damage, since the leakage of metabolites from disrupted cells could result in the release of nucleoside triphosphates, which could then serve as substrates for the generation of $\mathrm{PP}_{\mathrm{i}}$.

RELEASE OF PP; FROM

SUBCHONDRAL BONE

Local release of $P P_{i}$ from subchondral bone has been suggested as a further possible source of extracellular $\mathrm{PP}_{\mathrm{i}}$ in articular cartilage. Some polarity would be necessary so that $\mathrm{PP}_{\mathrm{i}}$ could reach subchondral bone through the blood supply on the metaphyseal side and then subsequently be released down a concentration gradient towards the articular surface. This could account for the observation that calcium pyrophosphate dihydrate deposits in the mid zone of articular. cartilage, since this would be the point at which $\mathrm{PP}_{\mathrm{i}}$ from the subchondral bone and calcium from the joint space would come together. ${ }^{56}$

\section{ALKALINE PHOSPHATASE AND REMOVAL OF PP $P_{\mathbf{i}}$ FROM THE \\ EXTRACELLULAR SPACE}

As in the case of intracellular $P P P_{i}$ metabolism, the major mechanism for removing $\mathrm{PP}_{\mathrm{i}}$ from the extracellular compartment is enzymatic hydrolysis. The addition of inorganic pyrophosphatase to extracellular fluids_for example, plasma - results in a pronounced reduction in the $P P_{i}$ concentration and therefore the reaction:

$$
P_{P_{i}} \rightarrow 2 P_{i}
$$

cannot be in equilibrium and the breakdown of extracellular $\mathrm{PP}_{\mathrm{i}}$ must be limited by the activity of hydrolytic enzymes.

The physiological importance of alkaline phosphatase activity in the extracellular hydrolysis of $\mathrm{PP}_{\mathrm{i}}$ has been demonstrated mainly by studies of patients with hypophosphatasia in whom a deficiency in alkaline phosphatase activity occurs. ${ }^{1458}$ There is a fourfold increase in the plasma $P_{i}$ concentration with a corresponding reduction in the rate constant of hydrolysis in the removal of $\mathrm{PP}_{\mathrm{i}}$ from the extracellular compartment. ${ }^{154457}$ Such observations establish that alkaline phosphatase does function as a pyrophosphatase in vivo and that is an ectoenzyme capable of hydrolysing substrates present in the extracellular compartment. It can be calculated that alkaline phosphatase may be responsible for the removal of as much as $80 \%$ of the $\mathrm{PP}_{\mathrm{i}}$ delivered to the extracellular compartment in normal individuals.

PROPERTIES OF THE PP HYDROLYTIC ACTIVITY OF ALKALINE PHOSPHATASE The properties of the hydrolytic activity of alkaline phosphatase towards $\mathrm{PP}_{\mathrm{i}}$ has been studied in a 
variety of tissues — for example, liver, kidney, and small intestine, ${ }^{58-60}$ bone $^{6162}$ and epiphyseal cartilage and matrix vesicles. ${ }^{63-65}$ This enzyme exhibits remarkably similar properties in a wide variety of tissues. The $\mathrm{pH}$ optimum of the $\mathrm{PP}_{\mathrm{i}}$ hydrolytic activity decreases with decreasing $P P_{i}$ concentration, so that at physiological concentrations of $\mathrm{PP}_{\mathrm{i}}$ approaches $\mathrm{pH}$ $7 \cdot 0$. Magnesium ions affect the activity in a complex manner and this effect appears to be influenced by the availability of substrate with an optimal activity occurring at a $\mathrm{Mg}^{++} / \mathrm{PP}_{\mathbf{i}}$ concentration ratio of $1: 1$. This led to the suggestion that the true substrate for the enzyme is $\mathrm{MgP}_{2} \mathrm{O}_{7}{ }^{2-}$ and that this cannot form if $P_{i}$ is present in excess over $\mathrm{Mg}^{++}$, whereas if $\mathrm{Mg}^{++}$is present in excess, $\mathrm{MgP}_{2} \mathrm{O}_{7}$ forms, which is inhibitory. In the presence of $\mathrm{Mg}^{++}, \mathrm{Ca}^{++}$is only slightly inhibitory but the activity is subject to inhibition by substrate and product $\left(P_{i}\right)$. The $\mathrm{Km}$ of alkaline phosphatase for $\mathrm{PP}_{\mathrm{i}}$ inhibition has been reported to range from $40-85 \mathrm{~mol} / 1$ but some of these differences may be accounted for by the use of different concentration ratios of $\mathrm{Mg}^{++}$to $\mathrm{PP}_{\mathrm{i}}$.

In a recent study, Howell's group ${ }^{54}$ have extracted and examined the properties of alkaline phosphatase derived from adult human articular cartilage. Virtually no activity could be obtained from 'normal' samples but appreciable amounts of the activity were obtained from patients with chondrocalcinosis and even higher activities were obtained from patients with osteoarthritis.

In articular cartilage derived from patients with osteoarthritis or chondrocalcinosis, there appear to be two forms of alkaline phosphatase, both of which possess hydrolytic activity towards $\mathrm{PP}_{\mathrm{i}}$ but whereas one form of the enzyme resembles the activity found in other tissues, the other appears to be activated rather than inhibited when $\mathrm{Mg}^{++}$is in excess over $\mathbf{P P}_{\mathrm{i}}$. It is not known, however, whether both forms of the enzyme are found in normal adult human articular cartilage.

Taken together, these studies of the hydrolytic activity of alkaline phosphatase towards $\mathrm{PP}_{\mathrm{i}}$ demonstrate that this activity can vary in response to a variety of physiological agents-for example, $\mathrm{Mg}^{++}, \mathrm{Ca},{ }^{++}$and
$P_{i}$, and further studies are needed to determine whether such agents regulate the breakdown of extracellular $\mathbf{P P}_{\mathrm{i}}$ in vivo.

IS A DEFECT IN CLEARANCE OF

PP $_{\mathrm{i}}$ FROM ARTICULAR

CARTILAGE INVOLVED

IN THE PATHOGENESIS OF

CHONDROCALCINOSIS?

There is little direct evidence for a defect in $\mathrm{PP}_{\mathrm{i}}$ clearance from articular cartilage in patients with idiopathic chondrocalcinosis. There have been reports that inorganic pyrophosphatase activity due to both alkaline phosphatase and glucose-6phosphatase is reduced in joint fluids from patients with chondrocalcinosis.66-69 In other studies, however, no change was observed either in the hydrolytic activity of alkaline phosphatase towards $P_{P}$ or in an inorganic pyrophosphatase activity, with an acid pH optimum, in joint fluids from these patients. ${ }^{70}$ Moreover, as noted earlier, Howell's group observed an increase rather than decrease in the $P P_{i}$ hydrolytic activity of alkaline phosphatase in articular cartilage derived from patients with chondrocalcinosis. ${ }^{54}$

However, some of the disease associations observed suggest that there is a defect in $P_{P}$ clearance from articular cartilage at least in some cases of chondrocalcinosis-for example, in hypophosphatasia. ${ }^{71}$ Similarly, the associations between chondrocalcinosis and hyperparathyroidism, ${ }^{72-74}$ haemochromatosis ${ }^{71}$ and hypomagnesaemia ${ }^{7375}$ could reflect the influence of $\mathrm{Ca}^{++}, \mathrm{Fe}^{++}$, and $\mathrm{Mg}^{++}$respectively on the pyrophosphatase activity of alkaline phosphatase.

CLINICAL CONDITIONS IN WHICH DISORDERS OF EXTRACELLULAR PP, METABOLISM OCCUR

Measurements of $P P_{i}$ in serum, plasma, or urine in a variety of clinical conditions have suggested that disorders of extracellular $P P_{i}$ metabolism do occur in some disease states, hypophosphatasia being the best example. However, plasma and serum $\mathrm{PP}_{\mathrm{f}}$ concentrations are also raised in about one third of patients with chronic renal failure, and the values return to normal after haemodialysis or renal transplant. ${ }^{76-78}$ An increase in the $\mathrm{PP}_{\mathrm{i}}$ content of bone has also been noted in some patients with chronic renal failure and it has been suggested that a relationship exists between the bone content of $\mathrm{PP}_{\mathrm{i}}$ and the extent of soft tissue calcification in these patients. ${ }^{79}$

The plasma concentration of $\mathrm{PP}_{\mathrm{i}}$ has been reported to be raised in some cases of acromegaly and this increase appears to be correlated with an increase in the plasma $P_{i}$ concentration. ${ }^{798}$ Plasma $\mathrm{PP}_{\mathrm{i}}$ is also raised in some patients with osteomalacia due to vitamin D deficiency, but apparently not in some of the inherited forms of vitamin D-resistant renal tubular rickets, nor in osteomalacia associated with total parenteral nutrition, ${ }^{15}$ (M. K. B. McGuire and others, paper presented at 14th Annual Meeting of American Society of Nephrology, 1981).

$A$ defect in urinary $\mathrm{PP}_{\mathrm{i}}$ excretion may contribute to formation of renal stones in some cases. In several studies it has been reported that urinary $P_{P}$ excretion is reduced in men who form stones but not women, with this effect being most marked in the $30-40$ age group. ${ }^{81-83}$

A defect in extracellular $P_{P_{i}}$ metabolism is unlikely in osteogenesis imperfecta as we have been unable to confirm the observation of Solomon's group that the serum $P_{i}$ concentration is raised in this disorder. ${ }^{8586}$

In this context it is important to note that measurements of $P_{i}$ in serum give values two to four-fold higher than in plasma. This is due to the release during blood clotting of $\mathrm{PP}_{\mathrm{i}}$ stored in the dense granules of platelets.

There is little evidence for any change in the plasma $\mathrm{PP}_{i}$ concentration in either rheumatoid arthritis or osteoarthritis. ${ }^{7780} 86-88$

In summary, there appears to be no systemic disorder in $\mathbf{P P}_{\mathrm{i}}$ metabolism associated with most cases of chondrocalcinosis.

\section{Physicochemical studies of calcium pyrophosphate crystal formation}

Little is known about the physicochemical conditions necessary for the formation of calcium pyrophosphate dihydrate (CPPD) 
crystals in articular cartilage and other sites in vivo. The problem can be considered from several points of view:

(a) What factors are necessary for initiating crystal deposition? (b) What determines the interconversions of different crystal forms of CPPD? (c) What influences the formation of the crystals, their solubility and removal from the joint?

INITIATION OF CRYSTAL

DEPOSITION

The formation of CPPD crystals in pathological conditions may be promoted in various ways. Firstly, the concentrations of calcium or $\mathbf{P P}_{\mathrm{i}}$ may be raised; the increased concentrations of $P P_{i}$ could result from either enhanced production or decreased removal from the joint, as, for example, in hypophosphatasia. ${ }^{14} 71$ By analogy, increased plasma calcium concentrations occur in hyperparathyroidism, although whether or not the association with deposition of CPPD crystals is mediated via raised calcium concentrations is at present unknown. Crystal formation might also be favoured by the presence of nucleating agents or by the removal of any neutral inhibitors of crystal formation, although currently very little is known about these possible mechanisms. In order to study some of these questions we have devised a simple method to define the conditions necessary for crystal deposition in vitro. ${ }^{89} 90$

The formation of crystals was studied in simple synthetic solutions which mimic extracellular and synovial fluids. At physiological concentrations of calcium $(1.5 \mathrm{mmol} / \mathrm{l})$ at $\mathrm{pH} 7.4$ and physiological ionic strength, crystals of calcium pyrophosphate were found to form within three days at $37^{\circ} \mathrm{C}$, when the $\mathrm{PP}_{\mathrm{i}}$ concentration was $40 \mu \mathrm{mol} / \mathrm{l}$ or higher. In the presence of $\mathrm{Mg}^{++}$at physiological concentrations $(0.5$ mmol/l), crystals formed only when the $\mathrm{PP}_{\mathrm{i}}$ concentration reached 175 mol/l. This contrasts with the concentrations of $\mathrm{PP}_{\mathrm{i}}$ found in normal synovial fluids (mean $3 \mathrm{~mol} / \mathrm{l}$; range 1 to $4 \mathrm{~mol}$ ) and in pseudogout fluid (mean $20 \mu \mathrm{mol} / \mathrm{l} ;$ range 5 to 60 $\mu \mathrm{mol} / \mathrm{l})$. In the presence of physiological concentrations (1 $\mathrm{mmol} / \mathrm{l})$ of inorganic phosphate (orthophosphate) the $P_{i}$ concentration required for crystal initiation was lowered to $75 \mathrm{~mol} / \mathrm{l}$. This reflects conditions which are the closest to physiological that have so far been explored. It appears, therefore, that the formation of CPPD crystals in synovial fluid would not be favoured in vivo. To explain where and why crystals form in the body one therefore needs to invoke additional mechanisms such as increased local concentrations of either calcium or $\mathrm{PP}_{\mathrm{i}}$, or the presence of nucleating agents.

The concept of nucleating mechanisms leading to crystal formation is an attractive one which requires further study. The association of pyrophosphate arthropathy with haemochromatosis ${ }^{71}$ was investigated and the possibility that iron salts might act as nucleating agents for crystal formation was tested in the crystal growth system in vitro. The presence of low concentrations of ferric salts $\left(\mathrm{Fe}^{++}\right.$at $\left.25 \mu \mathrm{mol} / \mathrm{l}\right)$ promoted crystal growth with the result that the amount of $\mathrm{PP}_{\mathrm{i}}$ needed for crystal formation was reduced to one quarter of that required in the absence of iron. ${ }^{89}$ It was thought that this effect may have been due to the colloidal nature of $\mathrm{Fe}^{++}$salts in solution at neutral $\mathrm{pH}$. Urate at physiological concentrations also has a small promoting effect on the precipitation of calcium pyrophosphate ${ }^{89}$ but it is doubtful whether this effect is potent enough to explain the association found between urate gout and pyrophosphate arthropathy.

Crystal formation in vitro increases rapidly as the $\mathrm{pH}$ rises through the range of $7 \cdot 2$ to $7 \cdot 4$ suggesting that in vivo a small change in $\mathrm{pH}$ could induce crystal formation without such large changes in the concentration of $\mathrm{Ca}$ and $\mathrm{PP}_{\mathrm{i}}$ being required. These results are interesting in relation to studies of Howell and Pita's group, ${ }^{\text {91-93 }}$ who have recorded high $\mathrm{pH}$ in extracellular fluid aspirates from epiphyseal cartilage by micropuncture techniques. The $\mathrm{pH}$ of fluid within articular rather than epiphyseal cartilage is, however, not known. In our studies of crystal formation in vitro a high $\mathrm{pH}$ promoted crystal formation.

The possible role of nucleation by epitaxy has also been explored and hydroxyapatite crystals were tested for their effect in our crystal growth experiments. At $40 \mu \mathrm{g} / \mathrm{ml}$ the added crystals raised the amount of pyrophosphate required to initiate CPPD crystal growth, presumably explained by their ability to absorb pyrophosphate, thereby making it unavailable. At lower concentrations ( $4 \mu \mathrm{g} / \mathrm{ml}$ ) preliminary results suggest that hydroxyapatite crystals are without effect, suggesting a balance between nucleating effects and surface adsorption of pyrophosphate. Further work is required to clarify this point.

CRYSTAL TRANSFORMATIONS

The type of CPPD crystals found naturally in vivo are predominantly in the triclinic form, although McCarty et $a l^{94}$ and Bywaters et $a l^{95}$ have reported the occurrence of the monoclinic form. Crystals produced in the three day incubations under the experimental conditions of Hearn and Russell ${ }^{89} 90$ were shown by $x$-ray diffraction to be orthorhombic in the absence of $\mathrm{Mg}^{++}$ and amorphous in the presence of physiological concentration of $\mathrm{Mg}^{++}$. Longer incubations of one month or more with added magnesium appear to allow the slow formation of crystals of the monoclinic type, followed by a slow transition to the triclinic form. The presence of $1 \mathrm{mmol} / \mathrm{l}$ phosphate considerably increased the rate of this transition, but even then failed to convert a significant proportion of crystals to the triclinic form.

The use of nucleating agents has so far failed to influence the type of crystal formed from solution. Hydroxyapatite crystals promote CPPD crystal formation but the types formed are orthorhombic and monoclinic. Similarly, addition of preformed $C \mathrm{PP}_{\mathrm{i}}$ crystals of these types leads only to further growth of those crystals and new growth of similar crystals, with no increase in transition to the triclinic forms.

These studies are based on microscopical identification and await confirmation by $x$-ray diffraction techniques. Work from the soil chemists of the Tennessee River Valley Authority, ${ }^{96}$ who investigated calcium pyrophosphates in relation to their use as fertilisers, provides valuable information about the potential transformations that can occur. A study of their results indicates that the monoclinic and triclinic varieties of CPPD crystals appear to 
represent the stable end products of a number of potential crystal transformations. Regardless of the physical nature of the first crystals to deposit, all crystals may therefore convert ultimately to monoclinic and triclinic varieties in vivo.

These studies shed light on the mystery of why the naturally occurring crystals are usually of the triclinic and occasionally of the monoclinic variety.

In an interesting study, Pritzker et $a l^{97}$ showed that the monoclinic and triclinic crystals could be made to form within silica and gelatin gels in vitro. Their conditions were close to, but did not match, the natural physiological state. Thus the concentrations of calcium and $\mathrm{PP}_{\mathrm{i}}$ they started with were considerably in excess of normal and the $\mathrm{pH}$ was below 6.0 .

Our own current work also suggests that these crystal conversions actually occur under simulated physiological conditions, but often take a long time, which means that the existence of these specific crystal forms in vivo may simply be an indication of the length of time available for crystal conversions to take place.

CRYSTAL FORMATION, SOLUBILITYANDREMOVALFROM THE JOINT

In cartilage CPPD crystal deposits appear initially in rims around cells ${ }^{93}$ and the large deposits are associated with empty cartilage lacunae indicating chondrocyte death. ${ }^{98}$ In the synovium, in contrast, CPPD crystals are found only in the phagocytic cells of the synovial membrane. ${ }^{99}$ Experimental studies using labelled crystals support the concept that these crystal deposits are sequestered from the synovial fluid rather than being formed in the synovium itself.

It seems probable, therefore, that CPPD crystals are formed initially in articular cartilage, and appear in the synovial fluid via a process of shedding rather than growth in situ of new CPPD crystals.

Bone is another tissue with a possible role in formation of CPPD. Bone lies close to the joint and the $\mathrm{PP}_{\mathrm{i}}$ concentrations might be expected to be high due to the ability of $\mathbf{P P}_{\mathbf{i}}$ to adsorb to hydroxyapatite surfaces. It is also possible that nucleating agents are located at the sites where crystal growth starts. The preferential location of CPPD deposits in articular cartilage and other joint structures suggests that there may be some abnormality of $P_{P}$ metabolism, metabolite diffusion, or of nucleation at these sites. $\mathrm{PP}_{\mathrm{i}}$ concentrations are raised in the synovial fluid but not in the plasma of patients with chondrocalcinosis and osteoarthritis, with chronically symptomatic joints. ${ }^{7086100101}$ It is uncertain whether this reflects local abnormalities in $\mathrm{PP}_{\mathrm{i}}$ metabolism or whether it is a result of dissolution of CPPD within the joint tissues.

As crystals are not regularly found in synovial fluid in osteoarthropathy, but only in pseudogout, despite the reported similarity in synovial fluid concentrations of $\mathrm{PP}_{\mathrm{i}}$ levels, it would appear that either the $\mathrm{PP}_{\mathrm{i}}$ is derived from different sources in the two conditions, or that specific mechanisms (such as nucleation of crystal growth) exist in the joints of patients with chondrocalcinosis which lead to CPPD crystal formation.

The high negative fixed charge density of articular cartilage ${ }^{102}$ may favour retention of cations. Maroudas $^{103}$ has suggested that cartilage may show some selectivity for the retention of calcium, which would lead to a rise in total calcium concentrations within the cartilage. The free ionic calcium concentration would, however, be expected to remain similar to that in synovial fluid. However, in pathological conditions, bound calcium might be released during degradation of proteoglycans and thereby initiate the formation of CPPD crystals.

Finally, it is possible that the raised $\mathbf{P P}_{\mathrm{i}}$ concentrations arise from dissolution of CPPD crystals. However, Camerlain et al ${ }^{104}$ found that crystals incubated in vitro with joint fluid showed very little exchange with ${ }^{32} \mathbf{P}-\mathbf{P P}_{1}$. This contrasts with the rapid turnover of $\mathbf{P P}_{\mathbf{i}}$ in vivo and suggests that either the solubility product for calcium pyrophosphate had already been attained or that one or more components of the turnover system in vivo were lacking. The problems of solubility are complex, however, and synthetic crystals behave differently from natural ones-possibly because of proteins which coat the crystals and impair dissolution. The phagocytosis of CPPD crystals is probably important in provoking the acute inflammatory reaction within the joint. CPPD, as with other crystal types which can provoke inflammation, has been shown to induce cell lysis. This may be the basis for the findings of chondrocyte lacunae in the vicinity of CPPD crystals in articular cartilage.$^{99}$ This may be due to the intracellular dissolution of crystals releasing large amounts of calcium and thereby poisoning the cell.

The question of why only certain patients with CPPD crystal deposition disease experience attacks of crystal synovitis remains to be determined. Presumably certain conditions have to be met before crystals will be 'shed' from the cartilage to provoke an attack. There appears to be an association of such attacks with major surgical interevention, especially where there is a significant postoperative decrease in serum calcium concentrations (parathyroidectomy, major surgery in the abdomen or thorax, etc). ${ }^{105}$ Any abrupt fall in serum calcium will lower the $[\mathrm{Ca}] \times\left[\mathrm{PP}_{\mathrm{i}}\right]$ ion product in the extracellular fluid bathing the CPPD crystals and may result in a loosening of these deposits within the lacunae due to crystal dissolution. The sudden decrease in size of the crystals may enhance their release from sites where they were hitherto tightly packed. Other mechanisms for release include minor surface fractures induced by trauma or wear.

We are grateful to the Arthritis and Rheumatism Council for their support of this work. A. Caswell acknowledges the receipt of a research fellowship from the Medical Research Council.

\section{References}

1 McCarty D J. Clinical assessment of arthritis. In: Hollander J L, ed. Arthritis and allied conditions. 9th ed. Philadelphia: Lea \& Febiger, 1979: 131-47.

2 Dieppe P A, Huskisson E C, Crocker P, Willoughby D A. Apatite deposition disease. A new arthropathy. Lancet 1976; i: 266-8.

3 Gaucher A, Fauré G, Netter P, Pourel $\mathrm{J}$, Duheille J. Identification des cristaux observes dans les arthropathies destructrices de la chondrocalcinose. Rev Rhum Mal Osteoartic 1977; 44: 407-14. 
4 Hoffman G S, Schumacher H R, Paul $\mathrm{H}$, et al. Calcium oxalate microcrystalline-associated arthritis in end-stage renal disease. Ann Intern Med 1982; 97: 36-42.

5 Kohn N A, Hughes R E, McCarty D J, Faires J S. The significance of calcium pyrophosphate crystals in the synovial fluid of arthritic patients: the pseudogout syndrome. Ann Intern Med 1962; 56: 738-45.

6 Bennett R M, Lehr J R, McCarty D J. Crystal shedding and acute pse udogout. Arthritis Rheum 1976; 19: 93-7.

7 Jacobelli S, McCarty D J, Wilcox D C, et al. Calcium pyrophosphate dihydrate crystal deposition in neuropathic joints. Four cases of polyarticular involvement. Ann Intern Med 1973; 79: 340-7.

8 Zitnan D, Sitaj S. Natural course of articular chondrocalcinosis. Arthritis Rheum 1976; 19: 363-90.

9 Zitnan D, Sitaj S. Mnohopecetna familiarlia Kalcifikaciz artikularynch chrupiek. Bratisl Lek Listy 1958; 28: 217-24.

10 Van der Korst J K, Geerards J. Articular chondrocalcinosis in a Dutch Pedigree. Arthritis Rheum 1976; 19: 405-9.

11 Bjelle A, Edvinsson U, Hagstam A. Pyrophosphate arthropathy in two Swedish families. Arthritis Rheum 1982; 25: 66-74.

12 Lust G, Faure G, Netter P, Gaucher A Seegmiller J E. Evidence of a generalised metabolic defect in patients with hereditary chondrocalcinosis. Arthritis Rheum 1981; 24: 1517-21.

13 McKeran R O, Andrews T M, Howell A, Gibbs D A, Chinn S, Watts R W E. The diagnosis of the carrier state for the Lesch-Nyhan Syndrome. $Q J$ Med 1975; 44: 189-205.

14 O'Duffy J D. Hypophosphatasia associated with calcium pyrophosphate dihydrate deposits in cartilage. Arthritis Rheum 1970; 13: 381-8.

15 Russell R G G, Bisaz S, Donath A, Morgan D B, Fleisch H. Inorganic pyrophosphate in plasma in normal persons and in patients with hypophosphatasia, osteogenesis imperfecta and other disorders of bone. J Clin Invest 1971; 50: 961-9.

16 Kornberg A. On the metabolic significance of phosphorylytic and pyrophosphorylytic reactions. In: Kasha M, Pullman D. eds. Horizons in biochemistry. New York: Academic Press 1962: 251-64.

17 Stetton D. Biosynthesis and pyrophosphate. Am J Med 1960; 28: 867-70.

18 Cook G A, King M T, Veech R L. Changes in liver inorganic pyrophosphate content during ethanol metabolism. Adv Exp Med Biol 1980; 132: 433-40.
19 Veech R L, Cook G A, King M T. Relationship of free cytoplasmic pyrophosphate to liver glucose content and total pyrophosphate to cytoplasmic phosphorylation potential. FEBS Lett 1980; 117, suppl: 65-72.

20 Flodgaard $\mathrm{H}$, Fleron $\mathrm{P}$. Thermodynamic parameters for the hydrolysis of inorganic pyrophosphate at $\mathrm{pH} 7 \cdot 4$ as a function of $\left[\mathrm{Mg}^{2+}\right],[\mathrm{K}+]$ and ionic strength determined from equilibrium studies of the reaction. $J$ Biol Chem 1974; 249: 3465-74.

21 Lawson J W R, Guynn R W, Comell N, Veech $R$ L. A possible role for pyrophosphate in the control of hepatic glucose metabolism. In: Hanson P W, Mehlman M A, eds Gluconeogenesis: its regulation in mammalian cells. New York: Wiley, 1976: 481-512.

22 Lawson J W R, Veech R L. Effects of $\mathrm{pH}$ and free $\mathrm{MG}^{2}$ on the Keq of the creatine kinase reaction and other phosphate hydrolysis and phosphate transfer reactions. J Biol Chem 1979; 254: 6528-37.

23 Guynn R W, Veloso D, Lawson J W R, Veech $R$ L. The concentration and control of cytoplasmic free inorganic pyrophosphate in rat liver in vivo. Biochem J 1974; 140: 369-75.

24 Lust G, Nuki G, Seegmiller J E. Inorganic pyrophosphate and proteoglycan metabolism in cultured human articular chondrocytes and fibroblasts. Arthritis Rheum 1976; 19: 479-87.

25 McGuire M B, Colman C H, Baghat N, Russell R G G. Radiometric measurement of pyrophosphate in cell cultures. Biochem Soc Trans 1980; 8: 529-30.

26 McGuire M K B, Bayliss M, Baghat N, Colman C H, Russell R G G. Pyrophosphate metabolism in human articular chondrocytes. Ann Rheum Dis 1981; 40: 207-8.

27 Lust G, Faure G, Netter P, Seegmiller $J$ E. Increased pyrophosphate in fibroblasts and lymphoblasts from patients with hereditary diffuse articular chondrocalcinosis. Science 1981; 214: 809-10.

28 Bjelle A. Cartilage matrix in hereditary pyrophosphate arthropathy. $J$ Rheumatol 1981; 8: 959-64.

29 Shatton J B, Shah H, Williams A, Morris $H \mathrm{P}$, Weinhouse $\mathrm{S}$. Activities and properties of inorganic pyrophosphatase in normal tissues and hepatic tumours of the rat. Cancer Res 1981; 41: 1866-72.

30 Felix R, Fleisch $H$. Purification and heterogeneity of inorganic pyrophosphatase of pig scapula cartilage. Biochem J 1975; 147: 103-9.

31 Furuyama S, Mitsuma M, Doi N, Sugiya H, Oyama S. Properties and distribution of inorganic pyrophos- phatase in rabbit dental pulp. $J$ Dent Res 1977; 56: 1339-1244.

32 Raja K B, Smith G P, Peters T J. Subcellular localization and properties of alkaline inorganic pyrophosphatase in human polymorphonuclear leucocytes. Clin Chim Acta 1981; 117: 33-41.

33 Mansurova S E, Belyakova T N, Kulaev I S. The role of inorganic pyrophosphate in energy metabolism of isolated mitochondria. Biochemistry (USSR) 1973; 38: 186-87.

34 Illingworth B, Cori C F. Glucose-6phosphatase and pyrophosphatase activities of homogenates of liver from patients with glycogen storage disease. Biochem Biophys Res Commun 1965: 19: $10-4$.

35 Hefferan P M, Howell R K. Genetic evidence for the common identity of glucose 6-phosphatase, pyrophosphatase-glucose phosphotransferase, carbamyl phosphateglucose phosphotransferase and inorganic pyrophosphatase. Biochim Biophys Acta 1977; 496: 431-5.

36 McCarty D J, Pepe P F, Solomon S D, Cobb J. Inhibition of human erythrocyte pyrophosphatase activity by calcium, cupric and ferrous ions. Arthritis Rheum 1970; 13: 336.

37 Felix R, Fleisch H. Properties of inorganic pyrophosphatase of pig scapula cartilage. Biochem J 1975; 147: 111-8.

38 Thuillier L. Purification and kinetic properties of human erythrocyte $\mathrm{Mg}^{2+}$-dependent inorganic pyrophosphatase. Biochim Biophys Acta 1978; 524: 198-206.

39 Oyama S, Mitsuma M, Furuyama S. Separation of inorganic pyrophosphatase from alkaline phosphatase in rabbit dental pulp. Int J Biochem 1981; 13: 105-7.

40 Egremovich N V, Volk E S, Baikov A A, Shakhov Y A. Isolation and primary characterization of two forms of inorganic pyrophosphatase from bovine heart mitochondria. Biochemistry (USSR) 1980; 45: 785-91.

41 Volk SE, Baykov A A, Duzkenko V S, Avaeva $\mathrm{S}$ M. Kinetic studies on the interactions of two forms of inorganic pyrophosphatase of heart mitochondria with physiological ligands. Eur J Biochem 1982; 125: 215-20.

42 Russell R G G, Wadstrom L B, Lindstedt S, Care A D, Bisaz S, Feisch $\mathrm{H}$ The origin or inorganic pyrophosphate in urine. Clinical Science 1969; 37: 419-29.

43 Jung A, Russell R G G. Bisaz S, Morgan D B. Fleisch $H$. The fate of intravenously injected pyrophosphate- ${ }^{32} \mathrm{P}$ in dogs. $A m$ Physiol 1970: 218: 1757-63.

44 Jung A. Preston C J, Walton R J, McGuire M K B. Russell R G G. ${ }^{32} \mathrm{P}$ 
kinetics in man utilizing ${ }^{32} \mathrm{P}$ orthophosphate and ${ }^{32} \mathrm{P}$ pyrophosphate. Mineral and Electrolyte Metabolism 1979; 2: 236.

45 Howell D S, Muniz D, Pita J C, Enis J E. Pyrophosphate release by osteoarthritic cartilage incubates. Arthritis Rheum 1976; 19: 488-94.

46 Ryan L M, Cheung H S, McCarty D J. Release of pyrophosphate by normal mammalian articular hyaline and fibrocartilage in organ culture. Arthritis Rheum 1981; 24: 1522-7.

47 Nuki G, Pritchard M H, Henderson W J, Lust G. Articular cartilage mineralization and inorganic pyrophosphate metabolism in chondrocytes. European Journal of Rheumatology and Inflammation 1978; 1: 105-14.

48 Felix $R$, Fleisch $H$. The effect of pyrophosphate and diphosphonates on calcium transport in red cells. Experientia 1977; 33: 1003-5.

49 Doherty M, Watt I, Dieppe P A. Localised chondrocalcinosis in postmeniscectomy knees. Lancet 1982; i: 1207-10.

50 Robison G, Butcher R W, Sutherland E W. Cyclic AMP. New York: Academic Press, 1971

51 Flodgaard H, Torp-Pedersen C A. A calcium ion-dependent adenosine triphosphate pyrophosphohydrolase in plasma membrane from rat liver. Biochem J 1978; 171: 817-20.

52 Torp-Pedersen C, Flodgaard H, Saermark $\mathrm{T}$. Studies on a $\mathrm{Ca}^{2+}$ dependent nucleoside triphosphate pyrophosphohydrolase in rat liver plasma membranes. Biochim Biophys Acta 1979; 571: 94-104.

53 Tran T T, Phillips J W, SchulzeSpecking A, Raseneck J, Decker K. Properties and biosynthetic connection of the nucleotide pyrophosphatase of rat liver plasma membrane and endoplasmic reticulum. Hoppe Seylers Z Physiol Chem 1981; 362: 305-16.

54 Tenenbaum J, Mainz O, Schumacher H R, Good A E, Howell D S. Comparison of phosphohydrolase activities from articular cartilage in calcium pyrophosphate deposition disease and primary osteoarthritis. Arthritis Rheum 1981; 24: 492-500.

55 Wuthier R E. Electrolytes of isolated epiphyseal chondrocytes, matrix vesicles and extracellular fluid. Calcif Tissue Res 1977; 23: 125-33.

56 McGuire M K B, Hearn P R, Russell R G G. Calcium pyrophosphate crystals (their relevance to calcium pyrophosphate dihydrate crystal deposition disease, pseudogout, chondrocalcinosis and pyrophosphate arthropathy): biochemical and physicochemical aspects. In: Maroudas A, Holborow M, eds. Studies in joint disease. Tunbridge Wells; Pitman Medical, 1980: 117-56.

57 Sorensen S A, Flodgaard H, Sorensen E. Serum alkaline phosphatase, serum pyrophosphat ase, phosphorylethanolamine and inorganic pyrophosphate in plasma and urine-a genetic and clinical study of hypophosphatasia. Monogr Hum Genet 1978; 19: 66-9.

58 Eaton R H, Moss D W. Inhibition of the orthophosphatase and pyrophosphatase activities of human alkaline phosphatase preparations. Biochem $J$ 1967; 102: 917-21.

59 Moss D W, Eaton R H, Smith J K, Whitby L G. Association of inorganic pyrophosphatase activity with human alkaline phosphatase preparations. Biochem J 1967; 102: 53-7.

60 Butterworth P J. The pyrophosphatase activity of pig kidney alkaline phosphatase and its inhibition by magnesium ions and excess of pyrophosphate. Biochem J 1968; 110: 671-5.

61 Eaton R H, Moss D W. Partial purification and some properties of human bone alkaline phosphatase. Enzymologia 1968; 35: 31-9.

62 Felix $R$, Fleisch $R$. The pyrophosphatase and $\mathrm{Ca}^{2+}-\mathrm{Mg}^{2+}$ [-ATPase activity] of purified calf bone alkaline phosphatase. Biochim Biophys Acta 1974; 350: 84-94.

63 Majeska R J, Wuthier R E. Studies on matrix vesicles isolated from chick epiphyseal cartilage. Association of pyrophosphatase and ATPase activities with alkaline phosphatase. Biochim Biophys Acta 1975; 391: 51-60.

64 Felix R, Fleisch H. Pyrophosphatase and ATPase of isolated cartilage matrix vesicles. Calcified Tissue Research 1976; 22: 1-7.

65 Fortuna R, Anderson H C, Carty R P, Sajdera $S$ W. Enzymatic characterization of the matrix vesicle alkaline phosphatase isolated from bovine epiphyseal cartilage. Calcif Tissue Int 1980; 30: 217-25.

66 Russell R G G, Bisaz S, Fleisch H,et al. Inorganic pyrophosphate in plasma urine and synovial fluid of patients with pyrophosphate arthropathy, chondrocalcinosis or pseudogout. Lancet 1970; ii: 899-902.

67 Good A E, Starkweather W H Synovial fluid pyrophosphate phosphohydrolase in pseudogout, gout and rheumatoid arthritis. Arthritis Rheum 1969; 12: 298.

68 Yaron M, Zurkowski P, Weiser H I, Yust I, Goldsmied A, Hermann E Pseudogout with low levels of alkaline phosphatase in the synovial fluid. Ann Intern Med 1970; 73: 751-6.

69 McCarty D J, Solomon S D, Warnock $M$ L, Paloyan E. Inorganic pyrophosphate concentrations in the synovial fluid of arthritic patients. $J$ Lab Clin Med 1971; 78: 216-9.

70 Jacobelli S, Kettlun A M, Sapag-Hagar $M$. Inorganic pyrophosphatase activity of the synovial fluid. Arthritis Rheum 1978; 21: 447-52.

71 Hamilton E B D. Disease associated with CPPD deposition disease. Arthritis Rheum 1976; 19: 353-7.

72 Eade A W T, Swannell A J, Williamson N. Pyrophosphate arthropathy in hypophosphatasia. Ann Rheum Dis 1981; 40: 164-70.

73 McCarty D J, Silcox D C, Coe F, et al. Diseases associated with calcium pyrophosphate dihydrate crystal deposition. Am J Med 1974; 56: 704-14.

74 Alexander G J M, Scott D G I, Dieppe $P$ A. Disease associations and laboratory investigations in pyrophosphate arthropathy. Ann Rheum Dis 1980; 40: 515-6.

75 Milazzo S C, Ahern M J, Cleland $L$ G, Henderson $D R$ F. Calcium pyrophosphate dihydrate deposition disease and familial hypomagnesaemia.J Rheumatol 1981; 8: 767-71.

76 David D S, Sakai S, Granda J, et al. Role of pyrophosphate in renal osteodystrophy. Trans Soc Artif Intern Organs 1973; 19: 440-5.

77 Silcox D C, McCarty D J. Quantification of inorganic pyrophosphate in biologic fluids; hyperpyrophosphataemia in some patients with osteoarthritis, pseudogout, acromegaly and uraemia. Arthritis Rheum 1973; 16: 132.

78 Bishop M, Russell R G G, Preston C J, Bisaz S, Fleisch H. Pyrophosphate and the development of bone disease in patients with renal insufficiency. In: Avioli L, Bordier P H, Fleisch $\mathrm{H}$, Massry S, Slatopolsky E, eds. Phosphate metabolism in kidney and bone Paris: Nouvelle Imprimerie Fournie, 1975: 157-69.

79 Alfrey A C, Solomons C C, Circillo J, Miller $\mathrm{N}$. Bone pyrophosphate in uraemia and its associations with extraosseous calcification.J Clin Invest 1976; 57: 700-5.

80 Camerlain M, Silcox D C, Lawrence A $M$, McCarty D J. Variation in plasma and urinary inorganic phosphate and pyrophosphate in normal subjects and in patients with acromegaly or osteoarthritis. $J$ Rheumatol 1980; 7: 365-74.

81 Russell R G G, Hodgkinson A. The urinary excretion of inorganic pyrophosphate by normal subjects and patients with renal calculus. Clinical Science 1966; 31: 51-62.

82 Bauman J M, Bisaz S, Felix R, Fleisch H, Ganz U, Russell R G G. The role of inhibitors and other factors in the 
pathogenesis of recurrent calcium-containing renal stones. Clin Sci Mol Med 1977; 53: 141-8.

83 Wikstrom B, Danielson B G, Ljunghall S, McGuire M K B, Russell R G G. Urinary pyrophosphate excretion in renal stone formers with normal and impaired renal acidification. Scand J Urol Nephrol 1981; 61, suppl: 1-17.

84 Armstrong D, Van Wormer D, Solomons C C. Increased inorganic serum pyrophosphate in serum and urine of patients with osteogenesis imperfecta. Clin Chem 1975; 21: 104-8.

85 Russell R G G, McGuire M K B, Hearn P R, Preston C J, Douglas D L, Jung A. Pyrophosphate revisited. Disorders of metabolism. Calcified Tissue International 1979; 27: A41.

86 Altman R D, Muniz O E, Pita J C, Howell D S. Articular chondrocalcinosis. Microanalysis of pyrophosphate in synovial fluid and plasma. Arthritis Rheum 1973; 16: 171-8.

87 Ryan L M, Kozin F, McCarty D J. Quantification of human plasma inorganic pyrophosphate. I. Normal values in osteoarthritis and calcium pyrophosphate deposition disease. Arthritis Rheum 1979; 22: 886-91.

88 Micheli A, Po J, Fallet G H. Measurement of soluble pyrophosphate in plasma and synovial fluid of patients with various rheumatic diseases. Scand J Rheumatol 1981: 10: 237-40.

89 Hearn P R, Russell R G G, Elliott J C. Formation product of calcium pyrophosphate crystals in vitro and the effect of iron salts. Clin Sci Mol Med 1978; 54: 29.

90 Hearn P R, Russell R G G. Formation of calcium pyrophosphate crystals in vitro. Implications for calcium pyrophosphate crystal deposition disease (pseudogout). Ann Rheum Dis 1980; 38: 222-7.

91 Cuervo L A, Pita J C, Howell P S. Ultra (microanalysis) of $\mathrm{pH}, \mathrm{pCO}_{2}$ and carbonic anhydrase at calcifying sites in cartilage. Calcif Tissue Res 1971; 7: 220-31.

92 Howell D S, Pita J C. Calcification of growth plate cartilage with special reference to studies on micropuncture fluids. Clin Orthop 1976; 118: 208-29.

93 Pita J C, Howell D S. In: Sokologg L, ed. The joints and synovial fluid. Vol. 1. New York: Academic Press, 1978.

94 McCarty D J, Kohn N N, Faires J S. The significance of calcium pyrophosphate crystals in the synovial fluid of arthritic patients: the pseudogout syndrome. 1. Clinical aspects. Ann Intern Med 1962; 56: 711-37.

95 Bywaters E G L, Dykes E, Pirie C, Rueben R. Crystal deposits in the discs, ligaments, joints and bursae of the spine. In: Proceedings of symposium on studies in joint disease. London: London Hospital Medical School, 1978.

96 Lehr J R, Brown E H. Chemical Engineering Bulletin. No. 6, Tennessee Valley Authority, USA, 1967: 22-3.
97 Pritzker K P H, Cheng P T, Adams M E, Nyburg J C. Calcium pyrophosphate dihydrate crystal formation in model hydrogels. J Rheumatol 1978; 5: 469-73.

98 McCarty D J. In: Holt P J L, ed. Current topics in connective tissue disease. London: Churchill Livingstone, 1975: 181-97.

99 McCarty D J, Palmer P W, Halverson P B. Clearance of calcium pyrophosphate dihydrate crystals in vivo. Arthritis Rheum 1979; 22: 718-27.

100 Grindey G B, Nichol C A. Microprocedure for determination of pyrophosphate and orthophosphate. Anal Biochem 1970; 33: 114-9.

101 Silcox D C, McCarty D J. Elevated inorganic pyrophosphate concentrations in synovial fluids in osteoarthritis and pseudogout.J Lab Clin Med 1974; 83: 518-31.

102 Maroudas A. Transport of solutes through cartilage: permeability to large molecules. J Anat 1976; 122: 335-47.

103 Maroudas A. Physicochemical properties of cartilage in the light of ion exchange theory. Biophysical J 1968; 8: 575 .

104 Camerlain M, McCarty D J, Silcox D C, Jung A. Inorganic pyrophosphate pool size and turnover rate in arthritic joints.J Clin Invest 1975; 55: 1373-81.

105 McCarty D J. Calcium pyrophosphate deposition disease. Arthritis Rheum 1957; 19: 275-85. 